\title{
Students' Characteristics Related to Their Performances in Problem-based Learning
}

\author{
Wahid, M. ${ }^{1}$, Kumara, A. ${ }^{2}$, Prihatiningsih, T.S. ${ }^{3}$, Rahayu, G.R. ${ }^{4}$, \& Werdhani, R.A. ${ }^{4}$
}

\begin{abstract}
Problem Based Learning (PBL) has been implemented as a major learning approach at the Faculty of Medicine, Universitas Indonesia (FMUI) since 2005. The learning environment and curriculum play an important role in students' performance. The characteristics of students may influence the PBL tutorial process and students' learning outcomes. This study aimed to examine the relationship between students' characteristics and their performances. By knowing students' characteristics, we can predict their future success, prevent their study delays and decrease student drop out numbers. The study population included all $2^{\text {nd }}, 4^{\text {th }}$ and $6^{\text {th }}$ semester students (total $=539$ ). Students' performance in the PBL discussion process was assessed using a standard evaluation form. Data was collected using questionnaires of students' characteristics and documents of students' achievements. Data was analyzed statistically using SPSS version 11.5 . The overall response rate was $69 \%$, with response rates of $71.5 \%, 63.5 \%$ and $72.1 \%$ from $2^{\text {nd }}, 4^{\text {th }}$ and $6^{\text {th }}$ semester students respectively. Students' method of admission and level of education correlated with the performance $(p<0.05)$. Discussion scores showed a moderate correlation with module scores $(r=0.398, p<0.001)$ and low correlation with GPA $(r=0.283$, $p<0.001)$. However, the module scores showed a strong correlation with GPA $(r=0.725, p<0.001)$. Students' admission and level of education affects students' academic outcomes. Discussion' and module scores can be utilized as a predictor of students' GPA.
\end{abstract}

Key words: grade point average

\section{Introduction}

Problem Based Learning (PBL) is one of learning strategies in which problems are presented early in the learning process. There are three major components of PBL: students, facilitators and triggers.

${ }^{1}$ Department of Microbiology, Faculty of Medicine, Universitas Indonesia, Pegangsaan Timur 16, Jakarta, 10320 Indonesia

${ }^{2}$ Department of Educational Psychology, Faculty of Psychology, GadjahMada University, Sosio Humaniora 1, Bulaksumur, Yogyakarta, 55781, Indonesia

${ }^{3}$ Department of Medical Education, Faculty of Medicine, GadjahMada University, Radioputro Building, Farmako, Sekip Utara, Yogyakarta, 55281, Indonesia

${ }^{4}$ Department of Community Medicine, Faculty of Medicine, Universitas Indonesia, Pegangsaan Timur 16, Jakarta, 10320 Indonesia

Corresponding Author:

Dr. Mardiastuti Wahid,

Department of Microbiology,

Faculty of Medicine, Universitas Indonesia,

PegangsaanTimur 16, Jakarta 10320, Indonesia.

E-mail: mardiastutiw@yahoo.com
The obstacles that are mostly found in the implementation of PBL are: poor development of triggers, inappropriate role of the tutor and inappropriate function of group discussion (inappropriate role of students in discussion process) (Dolmans et al., 2005). The success of a PBL tutorial process depends on some factors, such as students' characteristics and their attitudes toward PBL (Yee, et al., 2005). The study conducted by de Koning et al (2012) showed that the most significant factors influencing student achievement in a PBL curriculum were the students' grades prior to and during higher education and observed learning activities. Age, gender and nationality were less significant to student achievement. In contrast, a study on junior high school students revealed that gender was significantly correlated with later academic achievement (Zuffiano et al, 2013).

Since 2005, Problem Based Learning has been conducted at the Faculty of Medicine, Universitas Indonesia (FMUI). Facilitators comprise of medical doctors from preclinical departments as well as faculty members with a biomedical background. Staff members who are eligible to become a facilitator are ones who have been trained for PBL facilitation. Proper 
training of staff and students, support and responsibility of educational administrators are factors influencing the success of PBL (Usmani et al., 2011). PBL tutorial sessions are conducted twice a week, and are of 2-3 hours duration. Four to five triggers are presented to the students in a module which is held for six weeks. Facilitators evaluate the students' performance in every discussion session. To enrich students' knowledge, we conduct other learning activities such as lectures, laboratory practices, plenary discussions, video conferences, basic clinical skills and special topic discussions.

Other elements that can also play an important role in PBL implementation include learning resources for self-directed learning (Chan, 2009) and suitable assessment instruments (Kirschner et al., 2006). Therefore, before implementing PBL, FMUI provided access to discussion rooms, laboratories, skills lab, library books, journals and internet facilities. At the end of the module, scores of all learning activities are compiled as module scores. The module score is a compilation of knowledge $(60 \%)$ and learning process evaluation scores $(40 \%)$. Knowledge is assessed by conducting two formative and two summative tests. Only the summative test accounted as a knowledge score (theoretical $50 \%$, laboratory practice $10 \%$ ). The summative test items are multiple choice questions and scenario-based questions. The learning process is assessed using student evaluation forms $(20-30 \%)$. The percentages of other learning processes (notes, quizzes and laboratory practice) accounts for a total of $10-20 \%$. Other methods to assess students' learning progress is by conducting progress tests twice a year. The progress test questions are compiled from the module examination and the items bank.

During the educational process, some academic and non-academic problems may arise. The diversity of backgrounds, such as socio-economic, prior education/area of origin, personal problems, and many other aspects may affect student performance. Data taken from the faculties' counseling team showed that the number of students having academic and non-academic problems tended to increase from year to year. This eventually led to students being expelled or resigning since they could not reach the minimum requirements (unpublished data). Considering the facts mentioned above, we conducted PBL evaluation by investigating the characteristics of the students and their relationship to academic performance. Furthermore, we sought to examine the relationships between discussion, module and GPA scores.

\section{Methods}

Population: The population was the total number of regular students $(n=539)$ who enrolled at FMUI in neuroscience (2nd semester, $\mathrm{n}=186$ ), cardiovascular (4th semester, $n=181$ ) and hematology-oncology modules $\left(6^{\text {th }}\right.$ semester, $\left.n=172\right)$.

Data collection: A cross-sectional study was conducted by using several methods. Questionnaires were administered to students to determine gender, origin, student selection system and module attended/level of education. The selection systems are the national examination system, UI examination (conducted by Universitas Indonesia) and collaborative examination (conducted by some government universities, including UI). Other selection systems are the national admission system for highly qualified students, based on students' prior academic performances (talent scouting) and independent admission system for recommended students from rural areas. Students' performance during discussion was evaluated by the facilitators (scores ranging from 0-10). Students were assessed for their active participation, discipline, communication, sharing, dominancy and tendency to argue. Student achievement was assessed through the discussion process, module and Grade Point Average (GPA) scores.

Data analysis: validity and reliability of the students' performance instrument was examined beforehand. The distribution of variables was assessed using the KolmogorovSmirnov test, with a limit of $p>0.05$. The nonparametric test (Mann Whitney) was performed to analyze the 2 categorical data variables.

Since data collected showed an abnormal distribution, the correlations among numerical data variables were tested using the Spearman rank test. To compare the mean differences between categorical data variables $(>2$ categories) and numerical data variables with an abnormal distribution, we analyzed the data using the non-parametric test (Kruskal Wallis).

Students who were willing to be involved in the study were asked to sign the consent form after being briefed about the purpose of the research. Students were informed that the results of the study would not affect their academic performance. All data concerning students involved in this study was kept confidential. This study has obtained the ethical clearance from the Ethics Committee of the Faculty of Medicine, Universitas Gadjah Mada (UGM) and the FMUI. 


\section{Results}

The student evaluation form was valid $(p<0.05$, Cronbach's Alpha 0.723), except for the domination aspect. However, since the value of Cronbach's Alpha was not significantly different after the item was removed and dominance is an important aspect in assessing the group dynamics, it was decided to use all items.

\section{Students' characteristics}

The response rate was $69 \%$ (372 out of 539 students). The proportion of students that participated was $72.1 \%$ (6th semester students), $63.5 \%$ (4th semester students) and $71.5 \%$ (2nd semester students). Several categories of data variables were combined to be analyzed. The participants comprised more female $(56.2 \%)$ than male students $(43.8 \%)$. Students recruited from Java comprised $78 \%$ of participants, from Sumatra, 17\%, and from outside Java-Sumatra, $5 \%$. Admission was mostly through UI examination (33.6\%), joint selection (20\%), talent scouting (19.4\%), national examination $(16 \%)$, and independent examination systems (11\%).

\section{Students' achievement}

The median discussion score was 79 (min-max 60-94), while the median module score was 73 (min-max 41-87) and the median GPA was 3.36 (min-max 2.49-3.95). Table 1 presents some students characteristics related to discussion, module and GPA scores. It shows that students' level of education and selection system were significantly different in terms of students' achievement $(p<0.005)$. However, after the post hoc test, the discussion scores were not significantly different between groups of varied levels of education. The discussion score moderately correlated to module scores $(r=0.398, p<0.001)$ and showed a low correlation to GPA ( $r=0.283, p<0.001)$. The module score correlated to GPA $(r=0.725, p$ $<0.001)$.

Table 1. Discussion, modules and GPA scores based on students' characteristics in haematology, cardiovascular an neurosciences modules 2010-2011

\begin{tabular}{|c|c|c|c|c|c|c|c|c|c|}
\hline & \multicolumn{3}{|c|}{ Discussion scores } & \multicolumn{3}{|c|}{ Module scores } & \multicolumn{3}{|c|}{ GPA scores } \\
\hline & Median & $\begin{array}{l}\text { Min- } \\
\text { Max }\end{array}$ & $\mathrm{p}$ & Median & Min-Max & $\mathrm{p}$ & Median & Min-Max & $\mathrm{p}^{*}$ \\
\hline \multicolumn{10}{|l|}{ Gender } \\
\hline Male & 80 & $60-90$ & \multirow{2}{*}{0.052} & 73 & $41-84$ & \multirow{2}{*}{0.075} & 3.33 & $2.49-3.82$ & \multirow{2}{*}{0.549} \\
\hline Female & 79 & $62-94$ & & 74 & $64-87$ & & 3.36 & $2.72-3.95$ & \\
\hline \multicolumn{10}{|l|}{ Modules } \\
\hline $\begin{array}{l}\text { Haematology } \\
\text { (3rd year) }\end{array}$ & 79 & $60-94$ & \multirow{3}{*}{0.014} & 74 & $41-87$ & \multirow{3}{*}{$<0.001$} & 3.32 & $2.49-3.95$ & \multirow{3}{*}{0.086} \\
\hline $\begin{array}{l}\text { Cardiovascular } \\
\text { (2 } 2^{\text {nd }} \text { year) }\end{array}$ & 80 & $61-86$ & & 75 & $63-87$ & & 3.34 & $2.78-3.82$ & \\
\hline $\begin{array}{l}\text { Neuroscience } \\
\left(1^{\text {st }} \text { year }\right)\end{array}$ & 79 & $64-90$ & & 72 & $61-83$ & & 3.38 & $2.70-3.89$ & \\
\hline \multicolumn{10}{|l|}{ Student selection } \\
\hline Joint selection & 80 & $67-94$ & \multirow{5}{*}{0.016} & 74.5 & $65-87$ & \multirow{5}{*}{$<0.001$} & 3.36 & $2.72-3.86$ & \multirow{5}{*}{$<0.001$} \\
\hline Independent & 78 & $60-88$ & & 73 & $61-80$ & & 3.22 & $2.49-3.80$ & \\
\hline National exam & 79 & $63-85$ & & 73 & $41-84$ & & 3.27 & $2.59-3.81$ & \\
\hline Talent scouting & 80 & $62-87$ & & 74.5 & $66-85$ & & 3.50 & $3.01-3.95$ & \\
\hline Ul exam & 79 & $61-90$ & & 72 & $61-87$ & & 3.33 & $2.70-3.73$ & \\
\hline \multicolumn{10}{|l|}{ High school origin } \\
\hline Java & 79 & $60-90$ & & 73 & $41-87$ & & 3.34 & $2.49-3.89$ & \multirow{3}{*}{0.069} \\
\hline Sumatra & 80 & $67-88$ & 0.365 & 75 & $64-85$ & 0.155 & 3.37 & $2.83-3.95$ & \\
\hline $\begin{array}{l}\text { Other than Java } \\
\text { \& Sumatra }\end{array}$ & 80 & $62-94$ & & 74 & $67-87$ & & 3.41 & $3.04-3.86$ & \\
\hline
\end{tabular}


From the above test results, we can predict the GPA score by using these following formulas ( $p$ $<0.001$ ):

$$
\begin{gathered}
\mathrm{GPA}=0.784+0.001 \text { (discussion score })+ \\
0.034 \text { (module score })
\end{gathered}
$$

\section{Discussion}

There was no gender difference related to students' performance. Similarly, a study concerning gender-related differences in learning showed that there was no performance difference between male and female students in tutorials led either by staff or their peers (Kassab et al., 2005). However, group dynamic function was found to be better in female students, as they tended to listen and share more. In terms of written and practical examinations, there was also no gender difference (Kassab et al., 2005).

Most students were from Java Island, (the most populated island where the capital city is located). It can be explained that the recruited students were those with the best academic achievement and mostly originated from Java Island. There was no significant difference between students' area of origin and their achievement.

The level of education impacted student achievement, especially with regard to module and GPA scores. The module scores of the 2 nd semester students' were significantly lower than the 4th and 6th semester students. The GPA score of the 6th semester students was significantly higher than the 2nd semester students. The reason for these results could be that the 2nd semester students have to adapt to the new learning approach and environment, especially PBL which has not been introduced in high school. It was assumed that the more students gained experience in PBL, the higher the performance achieved.

Students can enter our medical school by choosing more than one selection system. The purpose of this policy is to support the students with low socio-economic levels to obtain the opportunity to study in qualified government universities. In this study we found that students recruited by talent scouting have a better performance than students recruited by other admission systems. All these examinations are based only on candidates' knowledge (sciences, math and Indonesian language), except for talent scouting which also considers extracurricular activities (nonacademic aspects) and other subjects. Admission via UI examination obtained the highest rate since it was particularly developed for entering UI. Unfortunately, students recruited by Ul examination performed less well than others (except those recruited by independent examination), therefore the admissions system should be improved by an appropriate method which is able to filter qualified prospective students. Medical students' selection in other countries is not dependent on one selection strategy. Their selection systems are not only based on knowledge, but also interview. According to Wilson et al. (2012), in Australia, many medical schools conduct personality tests, develop centralized selection centers and establish systems to increase the acceptance of students with low socio-economic background. A study conducted by Turner and Nicholson (2011) on the selection process of one medical school in England showed that there were many aspects to be reviewed prior to the students' interview phase. Aspects reviewed included: work experience, commitment to study in medicine, teacher recommendation and personal statement (self-reflection). The ideal candidates are expected to display high academic performance, enthusiasm and motivation. In addition, they also have to fulfil the requirements of becoming a qualified doctor. Similarly, Powis (1998) viewed that the most important aspect to be considered on student selection was the required qualities of candidates to become a qualified medical student and doctor. In addition, one should select a valid instrument and establish a procedure that is reliable, suitable and objective. Another study conducted by Lambe and Bristow (2011), aimed to predict student performance based on students' characteristics at the time of entry. They found that higher prior academic achievement at the time of entry to medical school, especially in science (chemistry), together with a higher interview score, were related to the probability of successful test performance in the future. According to Urling et al. (2009), the performance of medical students who were selected by a combination of cognitive and noncognitive assessments, was higher than students assessed by national lottery system based on pre-university GPA.

The module grade correlated with the GPA, since the module grade has a major contribution in determining the GPA. GPA score can be predicted by discussion and module scores. However, the module and GPA scores are not only determined by the discussion scores, since the discussion score only contributes a maximum of $30 \%$ to the module score. This situation explained the low to moderate correlation between discussion scores and GPA/module scores. Based on the 
fact that the discussion score was higher than the module score and there was no significant difference between the discussion score and level of education, we can assume the following:

1. Facilitators were not objective and too generous when assessing the tutorial process, so that students at all levels achieved similar and high scores.

2. The item was too difficult or not aligned with the learning objectives, therefore students faced difficulties in gaining a high score on the summative examination that will impact the module score.

Similar findings were also reported in a previous cardiovascular module report. The correlation between cognitive test scores and the discussion score was low $(r=0.218)$. Students complained that the assessment was difficult even though it was aligned with the learning objectives (Wahid, 2009). According to another research concerning FMUI students' achievement in a progress test held several years ago, the results supported the fact that the test item was more difficult compared to the National Board Examination. It was made evident by the lower scores on the progress test compared to the National Board Examination scores (Mardiastuti \& Werdhani, 2011).

The major limitation of this research was the limited number of completed questionnaires collected, which may be due to lack of students' interest to participate in this study. There is no conflict of interest regarding conducting this study.

\section{Conclusions}

Gender and high school origin did not correlate with students' performance. Students' level of education affected module scores; the higher the level of education, the higher the module scores obtained. Interestingly, the various admission systems also have an impact on some indicators of the students' performance, such as discussion, module and GPA scores.

Therefore, we strongly recommend our institution to improve the admission system by giving more opportunities to students, based on their prior performance. The selection system should consider not only knowledge, but also other aspects that can influence the success of medical students in becoming a good doctor. We propose to select medical students by reviewing their portfolios prior to interview, in addition to a specific psychometric (developed especially for medical students) and knowledge-based written test. Furthermore, we need further studies to improve the assessment system, so that it will increase students' achievement.

\section{References}

Azer, S. (2003) Assessment in a problem-based learning course, twelve tips for constructing multiple choice questions that test students cognitive skills, Biochemistry and Molecular Biology Education, 31, 6, pp. 428-434.

Chan, L.C. (2009) Factors affecting the quality of problem-based learning in a hybrid medical curriculum, Kaohsiung Journal of Medical Sciences, 25, pp. 254-257.

Dolmans, D.H.J.M., De Grave, W., Wolfhagen, I.H.A.P.\& van der Vleuten, C.P.M. (2005) Problem-based learning: future challenges for educational practice and research, Medical Education, 39, 7 , pp. 732-741.

De Koning, B.B., Loyens, S.M.M., Rikers, R.M.J.P., Smeets, G. \& van der Molen, H.T. (2012) Generation Psy: Student characteristics and academic achievement in a three year problembased learning bachelor program, Learning and Individual Differences, 22, pp. 313-323.

Kassab, S., Abu-Hijleh, M., Al-Shboul,Q.\&Hamdy,H. (2005) Gender-related differences in learning in student-led PBL tutorials, Education for Health, 18,2 , pp. 272-282.

Kirschner, P.A., Sweller, J. \& Clark, R.E. (2006) Why minimal guidance during instruction does not work: an analysis of the failure of constructivist, discovery, problem-based, experiential and inquiry-based teaching, Education Psychologist, 41,2 , pp. $75-86$

Lambe, P. \& Bristow, D. (2011) Predicting medical student performance from attributes at entry: a latent class analysis, Medical Education, 45, pp. 308-316.

Mardiastuti, H.W. \& Werdhani, R.A. (2011) Grade point average, progress test, and try out's test as tools for curriculum evaluation and graduates' performance prediction at the national board examination, Journal of Medicine and Medical Sciences, 2, 12, pp.1302-1305.

Powis, D. (1998) Select medical students, British Medical Journal, 317, pp.1149-1150.

Turner, R. \& Nicholson, S. (2011) Reasons selectors give for accepting and rejecting medical applicants before interview, Medical Education, 45, pp. 298-307.

Urlings-Strop, L., Stijnen, T., Themmen, A.P.N. \& Splinter,T.A.W. (2009) Selection of medical students: a controlled experiment, Medical Education, 43, pp. 175-183. 
Usmani, A., Sultan, S.T., Ali, S., Fatima, N. \& Babar, S. (2011) Comparison of students and facilitators' perception of implementing problem based learning, Journal of Pakistan Medical Association, 61,4 , pp. 332-335.

Wahid, M.H. (2009) Correlation between group discussion and examination result in Problem Based Learning, South East Asian Journal of Medical Education, 3, 2, pp. 9-14.

Wilson, I.G., Roberts, C.E., Flynn, M. \& Griffin, B. (2012) Only the best: medical student selection in Australia, Medical Journal of Australia, 196, 11, pp.1-5.
Yee, H.Y., Radhakrishnan, A. \& Ponnudurai, G. (2006) Improving PBLs in the International Medical University: defining the 'good PBL facilitator, Medical Teacher, 28, 6, pp. 558-560.

Zuffiano, A., Alessandri, G., Gerbino, M., Kanacri, B.P.L., Di Giunta, L., Milioni, M. \&Caprara, G.V. (2013) Academic achievement: The unique contribution of self-efficacy beliefs in selfregulated learning beyond intelligence, personality traits, and self-esteem, Learning and Individual Differences, 23, pp.158-162. 